Thorax (1969), 24, 399.

\title{
A controlled trial of anti-tuberculosis chemotherapy in the early complicated pneumoconiosis of coalworkers
}

\author{
J . D. BA L L, G. BERR Y, W. G . CLARKE, J . C. G I L S ON, \\ A ND J. THOMAS \\ with the assistance of \\ CATHERINE EXALL AND MARJORIE ROBERTS \\ From the Pneumoconiosis Research Unit, Llandough Hospital, Penarth, Glam.
}

\begin{abstract}
A controlled trial in coalminers under the age of 50 in South Wales with sputum-negative, early complicated pneumoconiosis was used to compare three regimes: (1) chemotherapy (rest in hospital and $1 \mathrm{~g}$. streptomycin, $200 \mathrm{mg}$. INH, $10 \mathrm{~g}$. PAS, for 3 months ; then $200 \mathrm{mg}$. INH, $10 \mathrm{~g}$. PAS for 9 months); (2) rest (in hospital for 3 months); and (3) a working group. The initial and three-year radiographs were assessed by two methods in $173(96 \%)$ of the 180 men entering the trial. No beneficial effect of chemotherapy was demonstrated and this factor was not related to the completeness of the chemotherapy. The variation between individuals in the rate of progression and in the development of new shadows was unrelated to chest symptoms, smoking habits, initial erythrocyte sedimentation rate, or special features in the initial radiographs, so these did not provide any useful predictive characteristics. Those with an initial negative Mantoux (1 T.U.) showed significantly less progression than those with a positive Mantoux. The lack of benefit and the short- and long-term complications of chemotherapy (weight gain, reduction in ventilatory capacity, dyspepsia, and streptomycin toxicity) show that this treatment is contra-indicated in miners with early complicated pneumoconiosis without a positive sputum. That new shadows develop during chemotherapy adds to the evidence from other sources that tuberculosis is unlikely to be a major factor in the pathogenesis of complicated pneumoconiosis in this area. Mycobacterium peregrinum (Runyon group IV) was isolated in three cases.
\end{abstract}

Complicated pneumoconiosis is more common in South Wales coalfields than in other areas of Great Britain. Over 2,000 cases were recognized in South Wales in a population of 72,000 working miners during the periodic radiographic survey by the National Coal Board between 1959 and 1963 (National Coal Board, 1964). Cochrane (1962) showed that in the Rhondda Fach in South Wales the attack rate of complicated pneumoconiosis (progressive massive fibrosis-P.M.F.) was related to the category of simple pneumoconiosis, and that $1-2 \%$ of miners with simple pneumoconiosis may be expected to develop complicated pneumoconiosis each year. How to treat miners with early complicated pneumoconiosis is therefore an important problem, especially as it has been shown that this form of pneumoconiosis can cause moderate or severe disability and increased mor- tality (Gilson and Hugh-Jones, 1955 ; Cochrane and Higgins, 1961 ; Cochrane, Carpenter, Moore, and Thomas, 1964).

Anti-tuberculosis chemotherapy had been tried frequently in sputum-negative cases in our patients in hospital but was not found to be effective, though on account of the slow progression seen in most cases of P.M.F. a beneficial long-term effect might have been undetected. Two previous controlled trials have been reported. Miall, Oldham, and Cochrane (1954) used isoniazid (100 mg. b.d. for two 3-month courses) shortly after its discovery. McCallum (1961) used isoniazid (200 mg. a day, PAS 10 g. a day for 12 months). Neither trial revealed any clear evidence of benefit, but the first trial used a regime not now regarded as adequate chemotherapy, and in the second trial a complete follow-up was not possible. 
If a further trial was to be made, it was essential that the scientific, technical, and ethical aspects should be considered in detail. To do this a committee was convened by the Medical Research Council under Professor C. H. Stuart-Harris in 1958. The unanimous conclusion of the committee was that a further trial was desirable but 'grave doubts were expressed on the possibility of completing the trial successfully'. The trial differed from most anti-tuberculosis chemotherapy trials in important respects which made it unusually difficult: (1) By definition the cases admitted did not have tubercle bacilli in the sputum, so a valuable index of the effect of therapy was removed. (2) The lesion in P.M.F. progresses more slowly than does tuberculosis. (3) The fibrotic nature of the lesions made it probable that the trial would be one-sided in the sense that we should be able to detect only 'no change' or 'progression' and would not have the group of 'improvement' on which the results of most trials of drugs for tuberculosis are based radiologically. (4) Studies in the Rhondda (Cochrane and Carpenter, 1956) had produced some evidence that the progression of the disease might be linked with physical activity, so a test of this factor had to be included in the design of the trial.

\section{PLAN OF TRIAL}

The original plan was to follow up over a period of at least three years 225 working miners randomly allocated into the three groups shown in Table I.

\section{T A B L E I}

PLAN AND THERAPEUTIC REGIMES OF TRIAL OF CHEMOTHERAPY IN EARLY COMPLICATED PNEUMOCONIOSIS OF COALWORKERS

\begin{tabular}{|c|c|c|c|}
\hline $\begin{array}{c}\text { Period } \\
\text { (months) }\end{array}$ & $\begin{array}{c}\text { Group 1 } \\
\text { 'Chemotherapy' }\end{array}$ & $\begin{array}{l}\text { Group } 2 \\
\text { 'Rest' }\end{array}$ & $\begin{array}{l}\text { Group 3, } \\
\text { 'Working' }\end{array}$ \\
\hline 3 & $\left.\begin{array}{l}\text { Hospital rest } \\
1 \text { g. Streptomycin } \\
200 \mathrm{mg} \text {. INH } \\
10 \mathrm{~g} \text {. PAS }\end{array}\right\}$ daily & $\begin{array}{l}\text { Hospital rest } \\
\text { Placebo }\end{array}$ & Working \\
\hline 9 & $\begin{array}{l}\text { Working } \\
200 \text { mg.INH } \\
10 \text { g. PAS }\} \text { daily }\end{array}$ & Working & Working \\
\hline 24 & $\begin{array}{l}\text { Working } \\
\text { No drugs }\end{array}$ & Working & Working \\
\hline
\end{tabular}

The group with hospital rest alone is unusual and was put in for the reasons mentioned, and because of the great importance of achieving an unambiguous result from a trial which might not be repeatable. At the time the trial was started, the results of the Madras study (Fox, 1962), showing the negligible benefit of hospital rest in tuberculosis, were not avait $\frac{\text { ? }}{0}$ able. In selecting the chemotherapy we were force $f$ to compromise between a regimen which was cer tainly adequate to control any active tuberculou focus and one which could and would be taken by a majority of miners when back at work. The addi tion of steroids was considered but rejected onaccount of the possible risk of complications and the absence of evidence of benefit in ward cases.

CRITERIA FOR SELECTION The subjects were working miners up to the age of 50, sputum-negative (6 of more negative cultures), and showing on the ches film opacities of a total diameter not exceeding $8 \mathrm{~cm}$. thought by a majority of a panel of three to bee examples of complicated pneumoconiosis of coals workers. In miners fulfilling these criteria the only reason for exclusion was a history of previous treat- ment with anti-tuberculosis drugs or the presence of another condition sufficiently severe to make i improbable that the man would be able to continue $\overrightarrow{0}$ his employment and be followed over a period of three years at least.

POPULATION SELECTION The trial started at the times of the first periodic survey by the National Coab Board. This ensured that working miners who camen within the oriteria for the trial could be recruited fromb the whole of the South Wales coalfield. The majority of men were recruited from this survey. A few came from those who applied for compensation to the Pneumoconiosis Medical Panels. The results are therefore, likely to be applicable at least to the whole of the South Wales area.

The purpose of the trial was explained to the miners and the Union representatives at all levels? Over two-thirds of those asked by the doctors of the National Coal Board or the Pneumoconiosis Panelsagreed to attend the Pneumoconiosis Research Unif for interview. Of those who attended, all but one who were suitable agreed to take part in the investiga-o tion. The trial remained open for three years and was closed after 180 out of the anticipated 225 hado been enrolled. One of three treatment regimes was. randomly selected within groups of six as the men attended for interview.

COURSE OF TRIAL At the initial interview a PA chestu radiograph, answers to a questionnaire on chest symptoms, previous illnesses, and smoking habits, and industrial history were obtained. A full physica $\bar{F}$ examination was made and specimens of blood, urines and sputum were collected. The forced expiratory volume $\left(F E V_{0.75}\right)$ and forced vital capacity (FVCБ were recorded (McKerrow, McDermott, and Gilson 1960), and a Mantoux test was done. These pro $\frac{?}{\Phi}$ cedures were repeated at $3,12,24$, and 36 months@

One man developed a TB-positive sputum and was withdrawn from the trial. Three men gave inter mittent positive cultures of anonymous mycobacterif but without clinical symptoms, so were retained it 
the trial. ${ }^{1}$ The size of the three groups during the progress of the trial is shown in Table II. The sustained co-operation shown by these figures-96\% were examined at 36 months and $94 \%$ regularly during the three years after admission to the trialshowed that the doubts of the committee were fortunately unfounded.

\section{T A B L E I I} NUMBER OF SUBJECTS

\begin{tabular}{l|c|c|c|c}
\hline & 'Chemotherapy' & 'Rest' & :'Working' & Totals \\
\hline $\begin{array}{l}\text { Admissions } \\
\text { Deaths }\end{array}$ & 60 & 59 & 61 & 180 \\
$\begin{array}{c}\text { Lapses at 3 years } \\
\text { No. examined for } \\
\text { progression at 3 }\end{array}$ & 1 & 2 & 0 & 3 \\
$\begin{array}{c}\text { years } \\
\text { No. examined regu- } \\
\text { larly (i.e., 0, 3, 12, } \\
24,36 \text { months) }\end{array}$ & 58 & 57 & 58 & 173 \\
\hline
\end{tabular}

The 'difference in the last two rows consists of semi-lapses, i.e., subjects who had lapsed during the trial but were persuaded to attend for a 3-year examination.

The three deaths were unrelated to treatment:

$I$ killed in accident underground;

1 died of coronary thrombosis:

1 died of $B$. proteus septicaemia.

COMPARABILITY OF THE THREE GROUPS Table III shows that the men in the three groups on entry did not differ significantly in age, years of underground work, weight, height, or ventilatory capacity. The average normal value of $F V_{1.0}$ for men aged 44 and

T A B L E I I I

COMPARISON OF GROUPS AT ENTRY

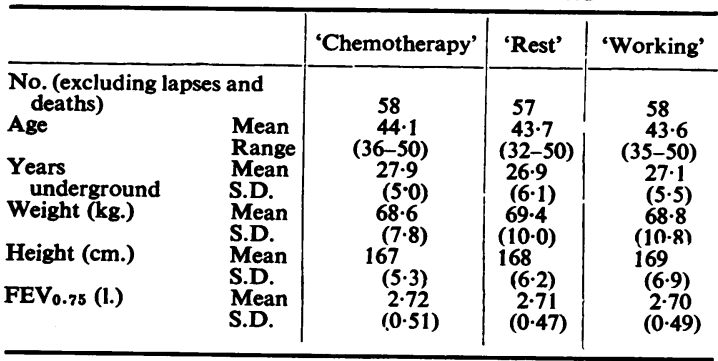

$168 \mathrm{~cm}$. in height is 3.31 . (Cotes, Rossiter, Higgins, and Gilson, 1966). This corresponds to an $\mathrm{FEV}_{0.75}$ of 2.95 1. (McKerrow, McDermott, and Gilson, 1960). Thus the average figure of $2 \cdot 71 \mathrm{l}$. (Table III) is only slightly below normal, confirming the view that early P.M.F. has little influence on ventilatory capacity (Cochrane and Higgins, 1961).

METHODS OF ASSESSMENT We relied principally on chest radiographs for assessing the effect of treatment. Special care was taken to see that each new film was technically indistinguishable from the man's film on

\footnotetext{
In all three cases the organism isolated was $M$. peregrinum, a rapidly growing bacillus belonging to Runyon group IV. This has been isolated frequently in South Wales and on present evidence does not appear to be pathogenic (Marks, 1968).
}

entry into the trial. All films were inspected for technique by W. G. C. and J. D. B. or J. C. G. before the man left on each visit.

Assessment of the films for change in the extent of the shadows was made in two ways: visual comparison by two observers independently; and a measurement of the area of the shadows. In the first method, two of the authors (J.D.B. and J.C. G.), with knowledge of the serial onder of the films but no knowledge of the treatment groups, assessed changes in the original shadows ('progression' or 'regression') or the development of new shadows at least $1 \mathrm{~cm}$.' in area ('attack'). Changes from the original shadows were read as definite progression (P), doubtful progression (?P), no change (NC), doubtful regression (?R), and definite regression (R). In the second method the same two observers traced the outline of the shadows on to transparent plastic sheets without knowing the group or the order of the films. The areas of the shadows were then measured, using squared paper, by a third observer. In this way we hoped to get as much unbiased information from the films as possible.

\section{RESULTS}

VISUAL COMPARISON OF RADIOGRAPHS The comparison of the films just before treatment and at approximately 36 months $^{1}$ is shown in Tables IV

T A B LE I V

AGREEMENT BETWEEN OBSERVERS

\begin{tabular}{|c|c|c|c|c|c|c|c|}
\hline & & $\mathbf{P}$ & ?P & $\underset{\text { NC }}{\text { Observer } Y}$ & ?R & $\mathbf{R}$ & \\
\hline & $\mathbf{P}$ & 18 & 9 & 2 & - & - & 29 \\
\hline & ?P & 12 & 15 & 6 & - & 1 & 34 \\
\hline Observer & NC & 21 & 15 & 66 & 4 & 2 & 108 \\
\hline \multirow[t]{3}{*}{$\mathbf{X}$} & ?R & 1 & - & - & - & 1 & 2 \\
\hline & $\mathbf{R}$ & - & - & - & - & - & $\mathbf{0}$ \\
\hline & & 52 & 39 & 74 & 4 & 4 & 173 \\
\hline
\end{tabular}

and $\mathrm{V}$ in relation to the two observers and the three treatment groups. Table IV shows that there was perfect agreement between the observers in 99 films $(57 \%)$. The discrepancies were consistent with observer $\mathbf{Y}$ interpreting smaller differences as indicative of a change than observer $X$. A random sample of 30 cases was re-read by both observers. Observer $X$ recorded the same reading in $25(83 \%)$ and within one category in $29(97 \%)$. Observer Y achieved $18(60 \%)$ and $28(93 \%)$. Although this might suggest that observer $Y$ is less repeatable than $X$ this is due in part to $Y$ 's

1The films were taken between 32 and 42 months in all except seven cases; in these, the final film was taken at $24,28,43,44$ $(\times 3)$, and 57 months. 
tendency to record smaller differences which were ignored by $\mathrm{X}$.

In Table $\mathrm{V}$ the only notable difference between the treatment groups is that observer $\mathbf{X}$ assessed more cases as 'no change' in the 'rest' group than in the other two groups, but this difference was not significant at the $5 \%$ level $(P=0.07)$. The Tab'e shows that the difference is due to fewer cases of 'doubtful progression' in the 'rest' group and not to a reduction in the number of 'definite progressions'.

T A B L E V

RADIOLOGICAL CHANGE IN THE THREE TREATMENT GROUPS

\begin{tabular}{|c|c|c|c|c|c|c|c|}
\hline & & $\mathbf{P}$ & ?P & $\mathrm{NC}$ & $\begin{array}{c}? \mathbf{R} \\
\text { and } \\
\mathbf{R}\end{array}$ & Total & $\begin{array}{l}\text { Attacks } \\
\text { and? } \\
\text { Attacks }\end{array}$ \\
\hline \multirow[t]{2}{*}{$\underset{\mathrm{X}}{\text { Observer }}$} & \multirow[t]{2}{*}{$\begin{array}{l}\text { Chemo- } \\
\text { therapy } \\
\text { Rest } \\
\text { Working }\end{array}$} & $\begin{array}{r}8^{(2)} \\
8^{(2)} \\
13^{(1)}\end{array}$ & $\begin{array}{r}15^{(1)} \\
6^{(1)} \\
13^{(2)}\end{array}$ & $\begin{array}{l}35^{(0)} \\
42^{(1)} \\
31^{(2)}\end{array}$ & $\begin{array}{l}0 \\
1 \\
1\end{array}$ & $\begin{array}{l}58 \\
57 \\
58\end{array}$ & $\begin{array}{l}3 \\
3 \\
5\end{array}$ \\
\hline & & 29 & 34 & 108 & 2 & 173 & 11 \\
\hline \multirow[t]{2}{*}{$\underset{Y}{\text { Observer }}$} & \multirow[t]{2}{*}{$\begin{array}{l}\text { Chemo- } \\
\text { therapy } \\
\text { Rest } \\
\text { Working }\end{array}$} & $\begin{array}{l}17^{(2)} \\
17^{(2)} \\
18^{(4)}\end{array}$ & $\begin{array}{l}12^{(0)} \\
10^{(2)} \\
17^{(2)}\end{array}$ & $\begin{array}{l}27^{(5)} \\
28^{(2)} \\
19^{(2)}\end{array}$ & $\begin{array}{l}2 \\
2^{(1)} \\
4\end{array}$ & $\begin{array}{l}58 \\
57 \\
58\end{array}$ & $\begin{array}{l}7 \\
7 \\
8\end{array}$ \\
\hline & & 52 & 39 & 74 & 8 & 173 & 22 \\
\hline
\end{tabular}

(Distribution of Attacks and? Attacks given above numbers)

Table $\mathrm{V}$ also shows the numbers of 'attacks' read by each observer; these show no significant relation to treatment. Observer $Y$ again read more abnormality than $\mathrm{X}$. If those cases read as 'no change' and 'attack' are excluded from the 'no change' category, the conclusions are not qualitatively altered.

The mean incidence of the two observers for progressions and attacks in the three groups is

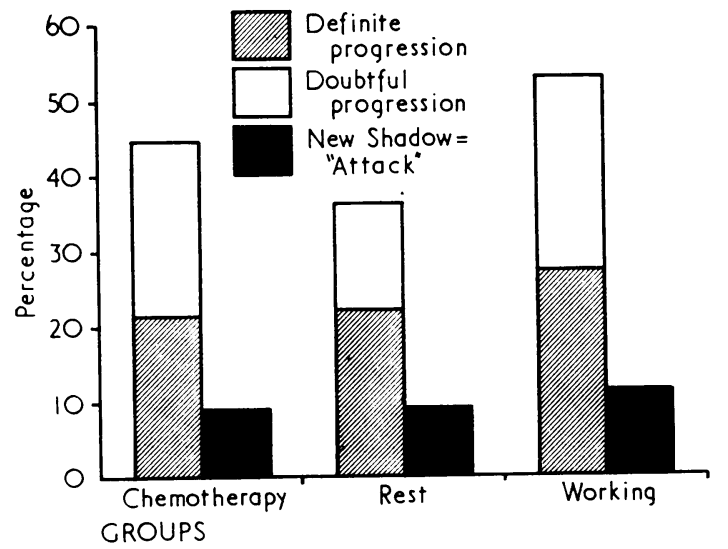

FIG. 1. Assessment of chest radiographs. Average of two observers (interval 36 months). shown in Figure 1. Although the 'working' group $\stackrel{\vec{s}}{+}$ showed somewhat greater progression, this differ-? ence does not approach statistical significance.

SHADJW AREAS The outlines of the shadows were traced on to transparent plastic sheets for 171 subjects by both observers and the areas drawn were ${ }^{\infty}$ measured for the 0 and 36-month films. Observer $\vec{O}$ $\mathrm{Y}$ tended to draw smaller areas than observer $\mathrm{X}, \overrightarrow{\vec{\omega}}$ the mean difference being $1.2 \mathrm{~cm} .^{2}$ The initial and $\stackrel{\omega}{\omega}$ 36-month areas (means of the two observers) are $\overrightarrow{2}$ shown for each group in Figure 2. The initial areas of the shadows varied from 2 to $35 \mathrm{~cm}^{2}$, but the group differences in the initial values were not $t_{\omega}^{+}$ significant when compared with the variation 8 between men within the treatment groups.

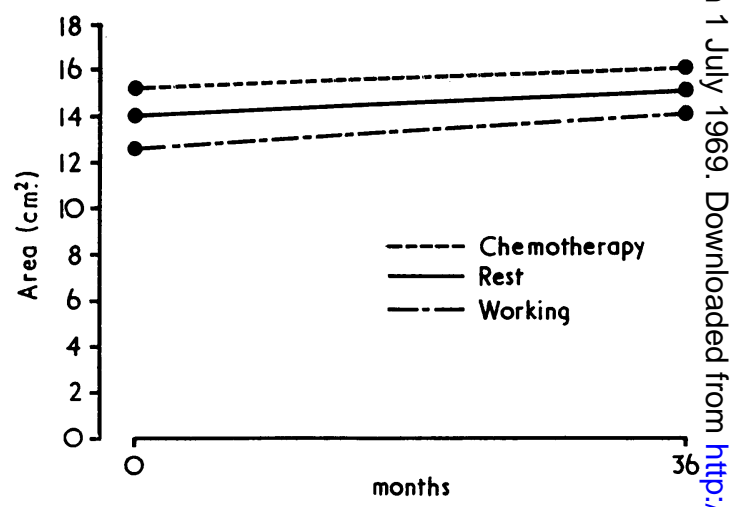

FIG. 2. Areas of shadows of complicated pneumocon iosis. Mean values $\left(\mathrm{cm}^{2}\right)$ of two observers (intervate 36 months).

To assess the group differences during the tria $\mathrm{B}$ the change in area of the shadows between the initial and 3-year films was calculated (making a proportional adjustment when the interval was not exactly 36 months).

The agreement between observers, ignoring con sistent differences between them, gives an indica tion of the accuracy of a value meaned over the two observers. For initial area the observer errof led to a standard deviation of $3.4 \mathrm{~cm}^{2}$ and forN change in area the corresponding figure was 1.8 $\mathrm{cm}^{2}{ }^{2}$ These values are $25 \%$ and $170 \%$ of the corresponding mean values and thus the effect of observer disagreement is relatively most marke for the change in area. If the absolute value of the area was of prime interest it would be better t. transform the areas to square roots to give a more symmetrical distribution within the population For the difference between the two occasionso however, the transformation is not necessary and the effect of the differences between observers io 
such that over $40 \%$ of the variation in increase in area (meaned over observers) is due to observer 'error', the remaining variation being due to actual variation between men within treatment groups.

The mean increase found by observer $X$ was $0.75 \mathrm{~cm}^{2}$ for the chemotherapy group and 1.0 $\mathrm{cm} .^{2}$ for both the rest and working groups. For observer $\mathbf{Y}$ the differences were larger, the means being $0.6 \mathrm{~cm}^{2}$ for the chemotherapy group, 1.2 $\mathrm{cm} .{ }^{2}$ for the rest group, and $2.0 \mathrm{~cm} .{ }^{2}$ for the working group. Differences between the treatment groups were not significant for either observer. However, both observers found a few cases with a large increase in area which appear heterogeneous with the overall distribution of the areas of the shadows. These cases occurred only in the rest and working groups but their number is so small that little statistical significance can be attached to the observation. These cases have an appreciable influence on the means of the rest and working groups, particularly for observer $\mathbf{Y}$ but, even after excluding these possible non-representative cases, there is no significant effect of treatment.

Summarizing the two methods of assessment, the only significant treatment effect was that one observer found that the rest group showed least progression. This effect $(P=0.07)$ was due to his recording fewer 'doubtful progressions' and more 'no changes', and was unsupported by the other observer. To accept the finding would imply that the chemotherapy had had a negative effect, a finding incompatible with any hypothesis yet advanced. It is, therefore, concluded that no treatment differences of any clinical importance are established by the trial.

It remains possible that within a group of nonresponders, sub-groups of responders are present. Both observers found a few cases with a large area increase in the rest and working groups but not in the chemotherapy group. If such sub-groups of potential responders to chemotherapy do exist it has not been possible to identify them in this trial by any features in the initial films. An attempt to do this was made by Dr. C. B. McKerrow who examined the first films and classified them into four grades according to the sharpness of the outline of the P.M.F. shadows and the degree of variability in the size of small opacities. Lack of clarity in the outline of large shadows might denote a process of extension, while variability in the size of the small opacities might indicate an early stage in the development of new massive lesions. The classification included both these attributes simultaneously; although this classifica- tion appeared to select subjects with subsequent radiological progression, it did not do so sufficiently precisely to aid interpretation of the trial.

COMPLETENESS OF THERAPY Of the 59 patients allocated to chemotherapy who entered hospital, 49 took the full dose ; two of the remainder took over $75 \%$ of the prescribed dose. We expected to meet difficulties during the nine months of treatment at home. A close watch on the completeness of treatment was made by weekly estimations of urine for isoniazid and fortnightly visits from our health visitor (C. E.). Eighty-six per cent of the weekly urine samples were obtained, and $89 \%$ were positive. Fifteen patients had less than 20 positive urine specimens in the nine months. Thirty-one of the patients took $90-100 \%$ of the prescribed dose, 15 took $70-90 \%, 9$ took $50-70 \%$, and 4 less than $50 \%$, these figures being estimated by the number of cachets remaining. These precautions did not exclude the possibility that uncooperative patients may have destroyed some of the cachets, or taken them only for a day before sending in their urine if they guessed the purpose of this test.

A total of 12 patients probably took less than half their total chemotherapy. We examined the possibility that these patients formed a large proportion of those with progression on the radiographs, but this was not so. Removing these patients from the analysis did not alter the conclusions reached in the previous section.

\section{DISADVANTAGES OF THERAPY}

Streptomycin vertigo Vertigo was sufficiently marked to stop treatment in five cases after 29$57 \mathrm{~g}$ had been given, at between the fourth and eighth weeks. The vertigo disappeared within a few weeks in one subject, but continued to be slight or moderate in the dark, though negligible in daylight, for over three years in four men.

A further nine cases had only slight vertigo and treatment was not stopped in these. The vertigo ceased within 2-8 weeks of completing the 3months course in eight cases but was still noticed occasionally nine months later by one man.

Dyspepsia Dyspepsia occurred at some time in 16 patients. It was fairly severe in seven of them. The dyspeptic symptoms in these cases started between the fifth and ninth month of treatment; as a result, the total number of cachets taken was between $50 \%$ and $80 \%$ of the prescribed dose over the nine months. The nine cases of slight dyspepsia developed in the course usually at about three months. Six of these completed their full 
treatment in spite of dyspepsia; the other three took between 50 and $85 \%$ of the prescribed dose. Six patients suffered from both vertigo and dyspepsia.

Weight rise Figure 3 shows that the average weight of the men in the two groups going to hospital rose steeply during the three months' admission, the rise being greater in the group without drugs. The mean weight rise of the rest group was $4.3 \mathrm{~kg}$. ; in those on chemotherapy with no dyspepsia, $2.8 \mathrm{~kg}$. ; and of the 19 men with dyspepsia from P.A.S., $2.0 \mathrm{~kg}$. This weight rise (not seen in the working group) delayed some miners returning to full work at once on account of increased breathlessness, but within 18 months the effect on weight was reversed.
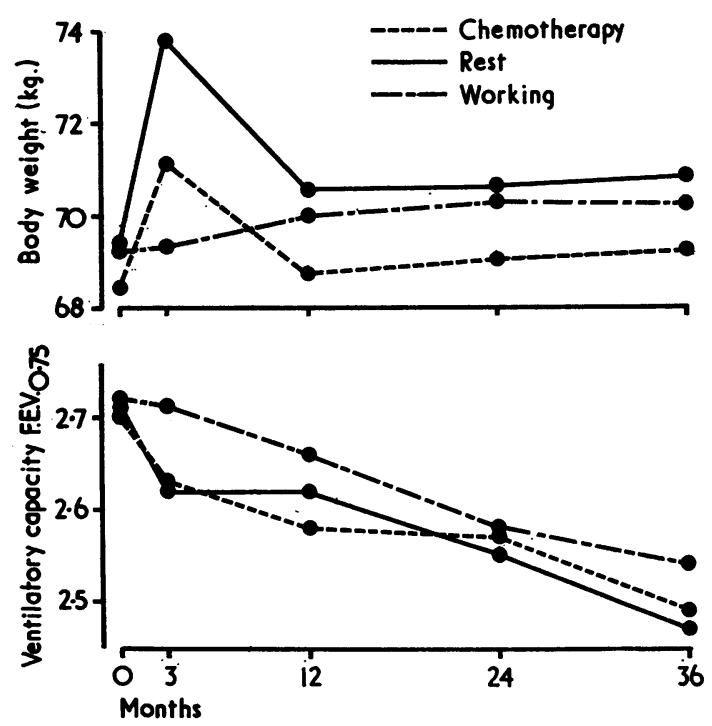

FIG. 3. Changes in body weight and ventilatory capacity in three treatment groups.

Fall in ventilatory capacity Figure 3 also shows the changes in ventilatory capacity. There was a sharp fall in the first three months in the two groups in hospital, but by 24 months the difference between the three groups had disappeared. These and other changes in lung function have been reported in detail elsewhere (Cotes and Gilson, 1967). It was concluded that the fall in F.E.V. was due to the weight increase and unrelated to the inactivity, the smoking habits, or the chemotherapy, except in so far as these factors affected the weight.
Employment We expected that a period in $\stackrel{\vec{F}}{?}$ hospital might affect the pattern of employment? compared with those in the working group. Table $\overline{\bar{O}}$ VI shows that the groups who were treated in hospital had a work record at one year veryळ similar to that of the working group. Of the five men in the chemotherapy group who were unem- ployed at one year, two had persistent strepto- mycin vertigo. One of these later returned to light $\vec{\omega}$ work; the other developed a disabling compen-? sation neurosis, partly the result of vertigo. The other three were unemployed for reasons unrelated to the trial.

T A B L E V I

CHANGES IN EMPLOYMENT AT ONE YEAR AFTER ENTRY

\begin{tabular}{|c|c|c|c|c|c|}
\hline & $\begin{array}{c}\text { No } \\
\text { Change }\end{array}$ & $\begin{array}{c}\text { Change of } \\
\text { Job } \\
\text { Under- } \\
\text { ground }\end{array}$ & $\begin{array}{c}\text { Left } \\
\text { Mining }\end{array}$ & $\begin{array}{l}\text { Unem- } \\
\text { ployed }\end{array}$ & Total seen \\
\hline $\begin{array}{l}\text { Chemo- } \\
\text { therapy } \\
\text { Rest } \\
\text { Working }\end{array}$ & $\begin{array}{l}44 \\
44 \\
50\end{array}$ & $\begin{array}{l}5 \\
9 \\
4\end{array}$ & $\begin{array}{l}2 \\
1 \\
2\end{array}$ & $\begin{array}{l}5 \\
3 \\
2\end{array}$ & $\begin{array}{l}56 \\
57 \\
58\end{array}$ \\
\hline
\end{tabular}

To summarize the disadvantages of the treat ment, the persistent ill-effect was vertigo in theo dark in four miners, two of whom remained unemployed for long periods. The transient ill-3 effects were weight gain, impaired ventilatory? capacity, and dyspepsia.

CORRELATION BETWEEN PROGRESSION AND OTHERO FINDINGS This trial gave an opportunity to look at correlations between radiological progressiono over three years and chest symptoms; smoking habits; E.S.R.; tuberculin sensitivity; ando rheumatoid factor.

Chest symptoms None of the symptoms recorded on the questionnaire at the start of the trial showed any correlation with radiological protn gression or change in area, nor were they related? to the treatment group.

Smoking Analysis of the relation of initiab smoking habits divided into four groups (non smokers; ex-smokers; light $(<15$ cigarettes/令 day); and heavy smokers ( $>15$ cigarettes/day) $\&$ showed no association with the initial area of theo shadows or the change of area over three years, Sedimentation rate Table VII shows the initia蛋 E.S.R. (Westergren) and change in E.S.R. aftestwo years, related to radiological progression for the two groups treated in hospital. For this puro 


\section{T A B L E V I I}

REST AND CHEMOTHERAPY GROUPS

RELATION OF RADIOLOGICAL CHANGE TO SEDIMENTATION RATE AT ENTRY AND CHANGE OF E.S.R. AFTER 2 YEARS

\begin{tabular}{|c|c|c|c|c|c|c|c|}
\hline & \multicolumn{3}{|c|}{$\begin{array}{l}\text { Initial E.S.R. } \\
(\mathrm{mm} \text {. in } 1 \mathrm{hr})\end{array}$} & \multicolumn{4}{|c|}{ Change of E.S.R. after 2 years } \\
\hline & $0-5$ & $>5$ & Total & $\begin{array}{c}\text { Decrease } \\
>2 \\
\mathrm{~mm} .\end{array}$ & $\begin{array}{l}\text { Change } \\
2 \text { mm. } \\
\text { or less }\end{array}$ & $\begin{array}{c}\text { Increase } \\
>2 \\
\mathrm{~mm} .\end{array}$ & Tota \\
\hline $\begin{array}{l}+P \\
\text { ?P } \\
\text { NC } \\
\text { ?R and } R\end{array}$ & $\begin{array}{r}10 \\
5 \\
14 \\
2\end{array}$ & $\begin{array}{r}14 \\
33 \\
35 \\
2\end{array}$ & $\begin{array}{r}24 \\
38 \\
49 \\
4\end{array}$ & $\begin{array}{r}7 \\
9 \\
14 \\
1\end{array}$ & $\begin{array}{r}7 \\
9 \\
22 \\
2\end{array}$ & $\begin{array}{r}9 \\
19 \\
13 \\
0\end{array}$ & $\begin{array}{r}23 \\
37 \\
49 \\
3\end{array}$ \\
\hline Totals & 31 & 84 & 115 & 31 & 40 & $\overline{41}$ & 112 \\
\hline
\end{tabular}

Two observers' readings combined: $\mathbf{P}=\mathbf{P}+\mathbf{P}$ or $\mathbf{P}+$ ? $\mathbf{P}$

$? \mathbf{P}=\mathbf{P}+\mathbf{N C}$ or $? \mathbf{P}+? \mathbf{P}$ or $? \mathbf{P}+\mathbf{N C}$

pose the radiological readings of the two observers were combined to give a single reading. Cases with a higher initial E.S.R. were not more likely to progress. We were, therefore, not able to confirm the findings of Stewart and his colleagues (1948). A correlation between radiological progression and increase of E.S.R. during two years is present ; of those whose E.S.R. increased by more than $2 \mathrm{~mm}$., $68 \%$ showed progression or doubtful progression compared with $45 \%$ in those with no change or a decrease of E.S.R. (P<0.05). This finding is of no material help in identifying in advance men likely to progress.

Mantoux tests These were made with 1 and 10 T.U. doses (old tuberculin) and read at 72 hours by the same observer (C. E.) throughout the trial. There was no relation in those with a positive test between the diameter of the reaction and the area of the radiographic shadow or the change in area over three years; but in those with a negative test (less than $1 \mathrm{~mm}$.) to 1 T.U. (32 out of 115 tested) definite progression occurred in only $3(9 \cdot 4 \%)$ compared with 21 out of $83(25 \cdot 3 \%)$ in those with a positive test. The difference is significant $(P=0.046)$ for a one-sided test.

A histogram of the numbers showing wheals of different sizes to 10 T.U. shows a distribution very similar to that of Hart, Cochrane, and Higgins (1963), who used 5 T.U., though the mean was naturally somewhat larger, $13.9 \mathrm{~mm}$. in our series compared with their mean of $10.4 \mathrm{~mm}$.

Rheumatoid factor Aggregated human $\gamma$ globulin (AHGG) was used to detect rheumatoid factor in the serum by the method described by Pernis, Vigliani, and Selikoff (1965). This measurement was made towards the end of the trial ; 157 subjects were tested and the titre at 36 months was used. Forty-two (27\%) showed a titre positive above 1 in 10,21 of these being positive at 1 in 80 or above. There was no correlation with radiological change. Those with negative titres had smaller initial shadow areas compared with those with positive titres $(\mathrm{P}<0.05)$, but there was no trend with height of titre. The change in area showed no relationship with titre.

Thus, in the search for indications of the likelihood that progression may occur in a patient with P.M.F., we have had little success. Symptoms and smoking habits are no guide, neither is the E.S.R. or AHGG titre. A negative Mantoux is associated with a reduced chance of progression.

\section{DISCUSSION}

The doubts expressed by the Medical Research Council committee on the practicability of this trial have in the event proved to be unfounded, mainly because of such ready co-operation from the miners and their Union officials and the help given by the staffs of the National Coal Board, the Ministry of Pensions and National Insurance (now Ministry of Social Security), and the Welsh Hospital Board.

The trial has shown that there are particular difficulties in measuring small changes in illdefined radiographic shadows in complicated pneumoconiosis even over a three-year period. After using the two methods of assessing the radiographs and two observers, we concluded that one year of anti-tuberculosis chemotherapy, with as high a dose as is practicable, had no significant effect on the progression of the disease followed over three years. Although this is true of the total series, there is a little evidence to indicate that there may be a small sub-group of patients who do respond to treatment, but unfortunately if they exist we found no means of predicting them, either from a special study of the characteristics of the shadows, or the E.S.R., or other factors. Those with a negative Mantoux 1 T.U. initially are slightly but significantly less likely to progress.

The conclusion, that the disease as measured by the radiographic appearance is not influenced by this treatment has practical therapeutic implications, because chemotherapy in hospital had appreciable transient and occasional long-term illeffects. In particular, the late effects of streptomycin toxicity, which may be only a slight inconvenience to most patients, may prevent a miner continuing to work underground because it is much more disabling in poor light and when carrying loads on uneven ground. We therefore conclude that in the absence of means of predicting those who will respond-if they exist-anti- 
tuberculosis chemotherapy is not justified in miners with P.M.F. who are sputum-negative for tubercle bacilli. The trial supports the conclusions of the only two previous controlled trials of this kind (Miall et al., 1954; McCallum, 1961). We considered the use of steroids and antituberculosis therapy in planning the trial but rejected the idea on account of the risk of complications. Our views are not altered after completion of the trial.

This trial adds a little to the evidence from other sources (Cochrane, 1962 ; Hart et al., 1963) that tuberculosis is probably not a major factor in the pathogenesis of P.M.F. As chemotherapy did not prevent the development of new shadows, tuberculous infection probably does not initiate the new foci of P.M.F. The lack of effect of chemotherapy on the progression suggests that tuberculosis is not responsible at this later stage in a majority of cases. However, the slender evidence from this trial and the earlier one by Miall et al. (1954), that chemotherapy may benefit a small proportion of cases even though these cannot be identified ahead, could be interpreted as supporting the view that P.M.F. has more than one aetiology. The diagnosis in life is radiological; it is known that some cases diagnosed as P.M.F. have a positive sputum and respond well to therapy (M.R.C./Miners' Treatment Centre Trials, 1963), but these cases cannot be identified for certain on radiological features alone. If P.M.F. has a multiple aetiology-silicotic in some cases, immunological in others, and tuberculous in a few-one might expect to find a case developing a positive sputum even though previously sputum negative. This occurred in one instance in this trial.

The negative results do not exclude the possibility that a mycobacterial infection resistant to the drugs used may also play a part in the pathogenesis of complicated pneumoconiosis. There is evidence of an association between coalworkers' pneumoconiosis and drug-resistant anonymous mycobacterial infection (Kamat, Rossiter, and Gilson, 1961), and three cases of intermittent positive sputum with $M$. peregrinum (Runyon group IV) were observed in the trial, but their course over three years did not differ obviously from the rest.

The excellent co-operation of the miners of South Wales and their Union representatives made this trial possible. We are deeply grateful for their support and understanding. We acknowledge the help at every stage of Dr. J. Rogan, Chief Medical Officer of the National Coal Board, and the Area Medical
Officers of the N.C.B., on whose initial interviews with the miners much depended. We had exceller support from the medical and administrative sta of the Pneumoconiosis Panels of the Ministry op Pensions and National Insurance. The Welsh Hos甲 pital Board made a special ward available at Talgart? Sanatorium, and the trial would have been impossible without the help of the staff there, including the late Dr. H. A. Ross, and Dr. Ivor Williams, Dr. J. Coutts, and Dr. W. Ganciwicz.

We wish to acknowledge the help of our colleague? at the Pneumoconiosis Research Unit, especially $\mathrm{M}_{\times}^{2}$ W. H. Roberts, and at the Miners' Chest Diseaseis Treatment Centre, especially Mrs. F. E. Willson.

We are especially grateful to Professor J. Croftor Professor A. L. Cochrane, Dr. I. T. T. Higgins, an\& Dr. W. E. Miall for their contribution to the planning and initial stages of the trial, and to Dr. J. Marks for the bacteriology of the sputum.

\section{REFERENCES}

Cochrane, A. L. (1962). The attack rate of progressive massive fibrosis. Brit. I. industr. Med., 19, 52 . and Carpenter, R. G. (1956). Factors influencing the radiologicál and Higgins, I. T. T. (1961). Pulmonary ventilation functions of coalminers in various areas in relation to the $X$-ray category of pneumoconiosis. Brit. J. prev. soc. Med., 15, 1.

- Carpenter, R. G., Moore, F., and Thomas, J. (1964). The more tality of miners and ex-miners in the Rhonnda Fach. Brit. J. indust Med., 21,38

Cotes, J. E., and Gilson, J. C. (1967). Effects of inactivity, weighฉ gain and antitubercular chemotherapy upon lung function in working coal-miners. Ann. occup. Hyg., 10, 327.

- Rossiter, C. E., Higgins, I. T. T., and Gilson, J. C. (1966) Average normal values for the forced expiratory volume in white Caucasian males. Brit. med. J., 1, 1016.

Fox, W. (1962). The chemotherapy and epidemiology of tuberculosis? Some findings of general applicability from the Tuberculosis Chemotherapy Centre, Madras. Lancet, 2, 413.

Gilson, J. C., and Hugh-Jones, P. (1955). Lung function in coalo workers' pneumoconiosis. Spec. Rep. Ser. med. Res. Coun (Lond.), No. 290.

Hart, J. T., Cochrane, A. L., and Higgins, I. T. T. (1963). Tuberculir sensitivity in coal workers' pneumoconiosis. Tubercle (Lond.) 3 44, 141.

Kamat, S. R., Rossiter, C. E., and Gilson, J. C. (1961). A retrő spective clinical study of pulmonary disease due to "anonymous mycobacteria" in Wales. Thorax, 16, 297.

McCallum, R. I. (1961). Treatment of progressive massive fibrosiso in coal miners. In Proceedings of the 13th International Congress
on Occupational Health, New York, 1960, p. 741.

McKerrow, C. B., McDermott, M., and Gilson, J. C. (1960). A s pirometer for measuring the forced expiratory volume with $\mathrm{a}=$ simple calibrating device. Lancet, 1, 149.

Marks, J. (1968). (Paper in preparation.)

Medical Research Council Committee on the Aetiology of Chronid Bronchitis (1965). Definition and classification of chronic bronchitis. Lancet, 1, 775.

(1960). Standardized questionaries on respiratory symptoms.
Brit. med.J., 2, 1665 .

Medical Research Council and Miners' Chest Diseases Treatmento Centre. (1963). Chemotherapy of pulmonary tuberculosis with pneumoconiosis. First report to the Medical Research Counci石 from the Joint Investigators. Tubercle (Lond.), 44, 47.

Miall, W. E., Oldham, P. D., and Cochrane, A. L. (1954). The' treatment of complicated pneumoconiosis with isoniazid Brit. J. industr. Med., 11, 186.

National Coal Board (1964). Report and Accounts. December $\vec{D}$ 1962-March 1964. Vol. 1. Report.

Pernis, B., Vigliani, E. C., and Selikoff, I. J. (1965). Rheumatoiס factor in serum of individuals exposed to asbestos. Ann. N.Y. Acad. Sci., 132, 112

Stewart, A. (1948). Pneumoconiosis of coalminers. A study of the disease after exposure to dust has ceased. Brit. J. industr. Med. 5,120 . 